\title{
Caricaceae endémicas del Perú
}

Blanca León ${ }^{1,2}$

${ }^{1}$ Museo de Historia Natural, Av. Arenales 1256, Aptdo. 14-0434, Lima 14, Perú

2 Plant Resources Center, University of Texas at Austin, Austin TX 78712 EE.UU.

blanca.leon@mail.utexas.edu

\section{Resumen}

La familia Caricaceae es reconocida en el Perú por presentar tres géneros y 15 especies (Brako \& Zarucchi, 1993; Ulloa Ulloa et al., 2004), principalmente arbustos y árboles bajos. En este trabajo reconocemos dos endemismos, ambos del género Carica. Estos taxones endémicos ocupan las regiones Matorral Desértico, Mesoandina y Bosques Muy Húmedos Montanos, entre los 1600 y 2700 m de altitud. Ninguno de estos taxones se encuentra representado en el Sistema Nacional de Áreas Naturales Protegidas por el Estado.

Palabras claves: Caricaceae, Carica, Perú, endemismo, plantas endémicas.

\section{Abstract}

The Caricaceae is represented in Peru by three genera and 15 species (Brako \& Zarucchi, 1993; Ulloa Ulloa et al., 2004), mainly shrubs and low trees. Here we recognize two endemic species in the genus Carica. These endemic taxa are found in the Desert Shrubland, Mesoandean and Very Humid Montane Forests regions, between 1600 and 2700 m elevation. Neither species is represented within Peru's protected area system.

Keywords: Caricaceae, Carica, Peru, endemism, endemic plants.

\section{Carica aprica V.M. Badillo}

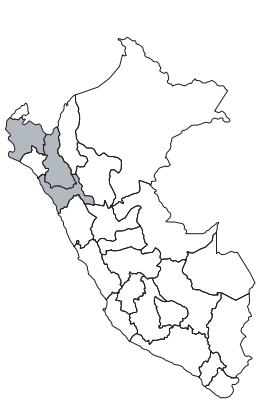

$$
\text { VU, B1a }
$$

Publicación: Monogr. Caric. 96-97, t. 17. 1971.

Colección tipo: P.C. Hutchison \& J.K. Wright 6688

Herbarios: US.

Nombre común: Odeque.

Registro departamental: CA, LL, PI.

Regiones Ecológicas: MDE, MA; 1600_ $2550 \mathrm{~m}$.

SINANPE: Sin registro.

Herbarios peruanos: HAO (3).

Observaciones: Arbusto conocido de la vertiente del Pacífico, en el norte del país, de las cuencas del Magdalena, Moche y Piura. Esta especie ocupa laderas pedregosas.

\section{Carica augusti Harms}

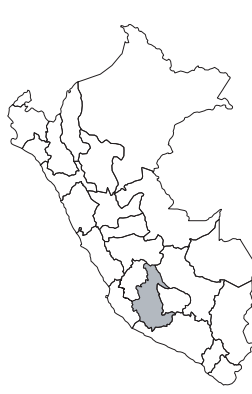

CR, B1ab(iii)

Publicación: Notizbl. Bot. Gart. BerlinDahlem 11: 280. 1931.

Colección tipo: A. Weberbauer 7563

Herbarios: BM, F, G, GH, K, NY, S, US.

Nombre común: Monte papaya.

Registro departamental: AY.

Regiones Ecológicas: BMHM; $2700 \mathrm{~m}$. SINANPE: Sin registro.

Herbarios peruanos: Ninguno.

Observaciones: Planta arbustiva de hasta $3 \mathrm{~m}$ de alto, conocida aparentemente sólo de la localidad original en la cuenca del Choimacota, un tributario del Apurímac, el cual ha sido escasamente herborizado. Weberbauer (1945) menciona la presencia de bosques húmedos montanos, entremezclados con laderas deforestadas y cubiertas de Pteridium, así como facies rocosas más secas. Incendios intencionales y deterioro ambiental podrían ser amenazas. 